\title{
Pengaruh Konsentrasi Pupuk Organik Cair Diperkaya Rhizobacteri Osmotoleran terhadap Pertumbuhan dan Hasil Tanaman Padi pada Kondisi Cekaman Kekeringan
}

\author{
DOI 10.18196/pt.2016.058.65-74
}

\author{
Chandra Kurnia Setiawan \\ Program Studi Agroteknologi, Fakultas Pertanian, Universitas Muhammadiyah Yogyakarta, \\ Jl. Lingkar Selatan, Kasihan, Bantul, Yogyakarta 55183, Indonesia Telp. 0274 387656, \\ e-mail:chandra_fp@umy.ac.id
}

\begin{abstract}
ABSTRAK
Penelitian ini bertujuan untuk mengetahui konsentrasi Pupuk Organik Cair diperkaya Rhizobakteri Osmotoleran yang tepat untuk meningkatkan pertumbuhan dan hasil tanaman padi pada kondisi cekaman kekeringan. Penelitian ini dilakukan dengan metode percobaan faktor tunggal yang disusun dalam rancangan acak lengkap (RAL). Perlakuan yang diujikan yaitu pemberian POC konsentrasi 5 ml/l + pupuk NPK 50\% dosis anjuran, POC konsentrasi 10 ml// + pupuk NPK 50\% dosis anjuran, POC konsentrasi 15 ml/I + pupuk NPK 50\% dosis anjuran, POC konsentrasi 20 ml/l + pupuk NPK 50\% dosis anjuran, dan pupuk NPK 100\% dosis anjuran dengan 3 ulangan. Hasil penelitian menunjukkan bahwa pemberian Pupuk Organik diperkaya Rhizobakteri Osmotoleran dapat mengurangi konsumsi pupuk NPK hingga 50\%. Perlakuan pemberian Pupuk Organik Cair dengan konsentrasi 15 ml/l + pupuk NPK 50\% dosis anjuran cenderung lebih baik mempengaruhi pertumbuhan dan hasil tanaman padi Ciherang pada kondisi cekaman kekeringan.

Kata kunci: Pupuk Organik Cair, Rhizobakteri Osmotoleran, Cekaman Kekeringan
\end{abstract}

\begin{abstract}
This study aimed to know the best concentration of Liquid Organic Fertilizer enriched with Rhizobacteri Osmotolerance to enhance plant growth and yield of rice in drought stress conditions. This research was conducted using single factor experiment arranged in a completely randomized design (RAL). The treatments tested are concentrations of POC $5 \mathrm{ml} / \mathrm{I}+$ + NPK fertilizer $50 \%$ recommendations, POC concentration of $10 \mathrm{ml} / \mathrm{I}+$ NPK fertilizer 50\% recommendations, POC concentration of $15 \mathrm{ml} / \mathrm{I}+$ NPK fertilizer $50 \%$ recommendations, POC concentration of $20 \mathrm{ml} / \mathrm{I}+$ NPK fertilizer $50 \%$ recommendations, and NPK fertilizer 100\% recommendations with three replications. The results showed that Liquid Organic Fertilizer enriched with Osmotoleran Rhizobacter can reduce NPK fertilizers until 50\%. Liquid Organic Fertilizer concentration of $15 \mathrm{ml} / \mathrm{I}+$ NPK fertilizers 50\% tend to improve the growth and production of Ciherang rice in drought stress conditions.

Keywords: Liquid Organic Fertilizer, Osmotoleran Rhizobacter, Drought Stress
\end{abstract}

\section{PENDAHULUAN}

Beberapa tahun terakhir, Indonesia melakukan impor beras tiap tahun. Data dari Badan Pusat Statistik (BPS) mencatat produksi beras nasional pada tahun 2008 adalah 29,266 juta ton beras dengan luas lahan sawah yang ditanami padi 12,343 juta ha. Angka kebutuhan konsumsi beras nasional menunjukkan 32 juta ton, sehingga pada tahun 2008 produksi padi Indonesia mengalami defisit 2,734 juta ton. Merujuk dari data BPS mengharuskan Indonesia mengimpor beras untuk mencukupi kebutuhan pokok pangan nasional.

Jalan yang dapat ditempuh guna mengurangi tingkat impor beras di Indonesia yaitu dengan program intensifikasi dan ekstensifikasi. Hasil dari program intensifikasi masih kurang dari harapan. Program lain yang dapat ditempuh yaitu ekstensifikasi. Melalui program ekstensifikasi, lahan-lahan baru mulai dibuka. Keterbatasan lahan produktif menjadi hambatan utama program ini. Menurut data BPS, konversi lahan produktif pertanian menjadi lahan non produktif sebesar $110.000 \mathrm{Ha} /$ th. Solusinya adalah program ekstensifikasi dilakukan di lahan marjinal. Hal ini didukung oleh potensi lahan marjinal di Indonesia sekitar 10 juta hektar. Salah satu masalah yang timbul adalah kekeringan pada lahan marjinal. Kekeringan mengakibatkan unsur hara 
tidak dapat terserap dengan baik oleh tanaman, sehingga tanaman mengalami stres dan lama kelamaan akan mati.

Salah satu cara mengurangi dampak kekeringan pada tanaman adalah pemberian inokulum Rhizobakteri Osmotoleran. Rhizobakteri Osmotoleran mempunyai kemampuan untuk meningkatkan ketahanan tanaman pada kondisi cekaman kekeringan, sehingga tanaman dapat tumbuh walaupun dalam kondisi tercekam. Bahan pembawa yang biasa digunakan sebagai bahan penyimpan inokulum bakteri pada umumnya yaitu medium Nutrien Cair. Bahan ini cukup mahal harganya. Penelitian sebelumnya mendapati bahwa pupuk organik cair dapat menggantikan medium Nutrien Cair (Khoiriyah, 2009).

Pupuk organik cair diperkaya Rhizobakteri Osmotoleran merupakan larutan yang kaya akan nutrisi dan mikrobia, sehingga pupuk organik cair ini dapat menambah kesuburan dan kemampuan bertahan tanaman dalam cekaman kekeringan di lahan marjinal. Kelebihan ini diharapkan dapat meningkatkan efisiensi penggunaan pupuk anorganik. Hal ini berarti dapat mengurangi tingginya penggunaan pupuk anorganik pada lahan marjinal (Khoiriyah, 2009).

Kesalahan pemberian pupuk organik cair dapat mengakibatkan kekurangan unsur hara dalam tanaman, sehingga tanaman tidak dapat menghasilkan produk secara maksimal. Kajian tentang konsentrasi pemberian pupuk organik cair diperkaya Rhizobakteri Osmotoleran di lahan marjinal masih kurang. Oleh karena itu perlu dikaji lebih lanjut konsentrasi pupuk organik cair diperkaya Rhizobakteri Osmotoleran di lahan marjinal untuk mendapatkan efektifitas dan efisiensi yang tepat.

Tujuan dari penelitian ini yaitu untuk mengetahui konsentrasi Pupuk Organik Cair diperkaya
Rhizobakteri Osmotoleran yang tepat untuk meningkatkan pertumbuhan dan hasil tanaman padi pada kondisi cekaman kekeringan.

\section{BAHAN DAN METODE}

Bahan penelitian yang digunakan meliputi Isolat Rhizobakteri Osmotoleran MPA-10 dan pupuk organik cair (Laboratorium Agrobioteknologi Fakultas Pertanian Universitas Muhammadiyah Yogyakarta), tanah Regosol, benih padi varietas Ciherang, dan larutan garam, pasir, medium NC, NA, LBA dan LBC, air steril.

Penelitian dilaksanakan di Laboratorium Agrobioteknologi dan Green House Fakultas Pertanian Universitas Muhammadiyah Yogyakarta. Penelitian dilakukan dengan metode percobaan faktor tunggal disusun dalam rancangan acak lengkap (RAL). Perlakuan yang dimaksud, yaitu:POC konsentrasi $5 \mathrm{ml} / \mathrm{l}+$ pupuk NPK 50 $\%$ dosis anjuran; POC konsentrasi $10 \mathrm{ml} / \mathrm{l}+$ pupuk NPK 50 \% dosis anjuran; POC konsentrasi $15 \mathrm{ml} / \mathrm{1}+$ pupuk NPK $50 \%$ dosis anjuran; POC konsentrasi $20 \mathrm{ml} / \mathrm{l}+$ pupuk NPK $50 \%$ dosis anjuran; pupuk NPK 100\% dosis anjuran. Tiap perlakuan diulang sebanyak tiga kali sehingga ada 15 unit percobaan. Tiap unit percobaan terdiri atas enam tanaman korban, tiga tanaman sampel dan satu cadangan, sehingga total bibit yang dibutuhkan sebanyak 150 bibit. Variabel pengamatan pada tanaman sampel meliputi tinggi tanaman, Jumlah daun, Jumlah anakan per tanaman, Berat biji kering per tanaman, Berat 100 biji. Sementara pengamatan pada tanaman korban meliputi Luas daun, Panjang akar, Berat segar akar, Berat kering akar, Berat segar tanaman, Berat kering tanaman, Dinamika populasi mikrobia dalam perakaran tanaman Padi.

Data dianalisis dengan sidik ragam (analysis of variance) pada á $=5 \%$. Apabila ada beda nyata 
antar perlakuan dilakukan uji lanjut dengan Uji Jarak Ganda Duncan (Duncan Mutiple Range Test) pada taraf á $=5 \%$. Kemudian Data periodik hasil pengamatan disajikan dalam bentuk tabel dan grafik histogram.

\section{HASIL DAN PEMBAHASAN}

\section{Dinamika Populasi Rhizobakteri}

Dalam penelitian ini digunakan perlakuan POC yang diperkaya Rhizobakteri Osmotoleran dengan populasi $6 \times 10^{6} \mathrm{CFU} / \mathrm{ml}$ (Khoiriyah, 2009). Ketersediaan air di dalam tanah dapat menyebabkan terjadinya cekaman yang disebabkan oleh kelebihan dan kehilangan air atau ketidakcukupan penyerapan atau kombinasi keduanya. Adanya air dalam tanah secara langsung mempengaruhi populasi Rhizobakteri Osmotoleran dalam tanah. Berdasarkan hasil analisis menunjukkan bahwa tidak adanya beda nyata antar perlakuan. Rerata dinamika populasi Rhizobakteri Osmotoleran disajikan pada Gambar 1.

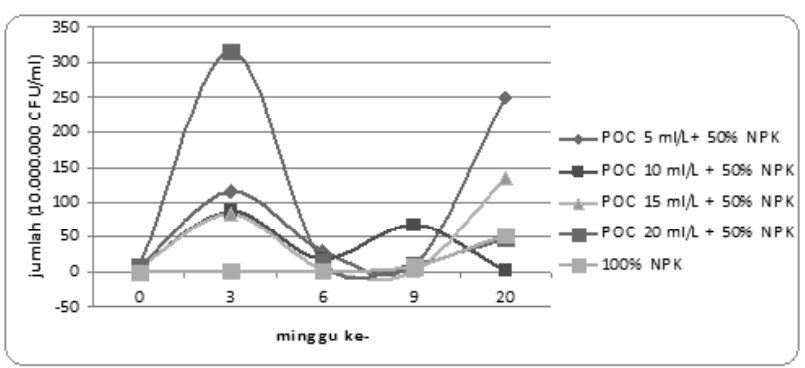

Gambar 1. Rerata Dinamika Populasi Rhizobakteri Osmotoleran pada Minggu ke-3, 6, 9 dan pada Saat Panen

Berdasarkan Gambar 1 dapat dijelaskan bahwa tingginya populasi Rhizobakteri pada perlakuan POC $5 \mathrm{ml} / \mathrm{l}, 15 \mathrm{ml} / \mathrm{l}$ dan $20 \mathrm{ml} / \mathrm{l}$ dalam perakaran pada minggu ke-3 dikarenakan tanaman baru saja diberikan perlakuan POC. Penurunan populasi Rhizobakteri pada minggu ke-6 dan 9 dikarenakan Rhizobakteri yang diberikan banyak yang mengalami kematian.

Sementara perlakuan pemberian POC dengan konsentrasi $10 \mathrm{ml} / 1$ pada minggu ke-6 mengalami penurunan, namun pada minggu ke-9 populasi Rhizobakteri pada perlakuan ini mengalami peningkatan. Pada saat panen perkembangan Rhizobakteri pada perlakuan ini mengalami penurunan kembali. Hal ini dimungkinkan karena Rhizobakteri pada minggu ke-6 mengalami adaptasi terhadap keadaan lingkungan barunya, sehingga beberapa Rhizobakteri mengalami fase kematian. Akan tetapi pada saat minggu ke-9 Rhizobakteri dapat aktif membelah kembali dikarenakan keadaan lingkungan perakaran yang mendukung perkembangan Rhizobakteri. Penurunan populasi bakteri diduga akibat kurangnya sintesis eksudat akar ke area rizhosfer. Karakterisasi Rhizobakteri Osmotoleran dapat dilihat pada Tabel 1.

Tabel 1. Karakteristik Isolat Rhizobakteri Osmotoleran

\begin{tabular}{lccccc}
\hline Keterangan & $\begin{array}{c}\text { Isolat hasil } \\
\text { pemurnian }\end{array}$ & $\begin{array}{c}\text { Isolat pada } \\
\text { tanah umur } \\
3 \text { minggu }\end{array}$ & $\begin{array}{c}\text { Isolat pada } \\
\text { tanah umur } \\
6 \text { minggu }\end{array}$ & $\begin{array}{c}\text { Isolat pada } \\
\text { tanah umur } \\
9 \text { minggu }\end{array}$ & $\begin{array}{c}\text { Isolat pada } \\
\text { tanah saat } \\
\text { panen }\end{array}$ \\
\hline Warna & $\begin{array}{c}\text { Putih } \\
\text { kekuningan }\end{array}$ & $\begin{array}{c}\text { Putih } \\
\text { kekuningan }\end{array}$ & $\begin{array}{c}\text { Putih } \\
\text { kekuningan }\end{array}$ & $\begin{array}{c}\text { Putih } \\
\text { kekuningan }\end{array}$ & $\begin{array}{c}\text { Putih } \\
\text { kekuningan }\end{array}$ \\
$\begin{array}{l}\text { Bentuk } \\
\text { koloni }\end{array}$ & Circulair & Circulair & Circulair & Circulair & Circulair \\
$\begin{array}{l}\text { Bentuk tepi } \\
\text { Elevasi }\end{array}$ & Undulate & Entire & Entire & Entire & Entire \\
$\begin{array}{l}\text { Struktur } \\
\text { dalam }\end{array}$ & $\begin{array}{c}\text { Coarsely } \\
\text { Granular }\end{array}$ & $\begin{array}{c}\text { Coarsely } \\
\text { Granular }\end{array}$ & $\begin{array}{c}\text { Finely } \\
\text { Granular }\end{array}$ & $\begin{array}{c}\text { Finely } \\
\text { Granular }\end{array}$ & $\begin{array}{c}\text { Franular } \\
\text { Giamely }\end{array}$ \\
Diamer & $0,8-3$ mm & $2,8-3,2$ mm & $\begin{array}{c}0,12-0,22 \\
\text { mm }\end{array}$ & $\begin{array}{c}0,11-0,2 \\
\text { mm }\end{array}$ & $\begin{array}{c}0,11-0,16 \\
\text { mm }\end{array}$ \\
Bentuk sel & Cocus & Cocus & Cocus & Cocus & Cocus \\
Sifat gram & Negatif & Negatif & Negatif & Negatif & Negatif \\
\hline
\end{tabular}

Pada Tabel 1 terlihat bahwa ada perubahan pada bentuk tepi, struktur dalam dan diameter koloni. Perubahan sifat bakteri tersebut dikarenakan bakteri mengalami proses adaptasi selama masa penyimpanan dan pada saat aplikasi.

Bentuk adaptasi bakteri guna mempertahankan hidupnya yaitu dengan mengalami perubahan ukuran, permukaan sel dan aktivitas metabolisme. Purwoko (2007) menyatakan bahwa sel bakteri akan mengalami fase statis pada saat 
pemindahan pada medium baru, sel bakteri melakukan proses adaptasi yang meliputi sintesis enzim sesuai dengan mediumnya dan pemulihan terhadap metabolik yang bersifat toksik pada waktu di medium lama, sehingga bakteri melakukan pengecilan ukuran sel.

\section{Pertumbuhan Tanaman}

Hasil analisis tinggi tanaman menunjukkan bahwa tidak ada beda nyata antar perlakuan. Pemberian POC yang diperkaya Rhizobakteri Osmotoleran cenderung lebih baik dibandingkan dengan tanpa pemberian POC diperkaya Rhizobakteri. Hal ini dikarenakan peran Rhizobakteri Osmotoleran selain dapat membantu tanaman dalam meningkatkan ketahanan dalam kondisi cekaman kekeringan juga dapat menfiksasi N, sehingga pemberian POC diperkaya Rhizobakteri Osmotoleran lebih efisien dalam penggunaan pupuk NPK. Rerata tinggi tanaman disajikan pada Tabel 2 dan Gambar 2.

Tabel 2. Rerata Tinggi Tanaman, Jumlah Anakan, Jumlah Daun dan Luas Daun pada Umur Tanaman 14 Minggu

\begin{tabular}{lcccc}
\hline \multicolumn{1}{c}{ Perlakuan } & $\begin{array}{c}\text { Tinggi } \\
\text { tanaman }(\mathrm{cm})\end{array}$ & $\begin{array}{c}\text { Jumlah } \\
\text { Anakan }\end{array}$ & $\begin{array}{c}\text { Jumlah daun } \\
\text { (helai) }\end{array}$ & $\begin{array}{c}\text { Luas Daun } \\
(\mathrm{cm})\end{array}$ \\
\hline POC $5 \mathrm{ml} / \mathrm{l}+50 \% \mathrm{NPK}$ & $72,12 \mathrm{a}$ & $15,89 \mathrm{a}$ & $46,32 \mathrm{a}$ & $152,83 \mathrm{a}$ \\
POC $10 \mathrm{ml} / \mathrm{l}+50 \% \mathrm{NPK}$ & $71,54 \mathrm{a}$ & $14,33 \mathrm{a}$ & $42,89 \mathrm{a}$ & $118,00 \mathrm{a}$ \\
POC $15 \mathrm{ml} / \mathrm{l}+50 \% \mathrm{NPK}$ & $72,03 \mathrm{a}$ & $12,78 \mathrm{a}$ & $37,78 \mathrm{a}$ & $113,00 \mathrm{a}$ \\
POC $20 \mathrm{ml} / \mathrm{l}+50 \% \mathrm{NPK}$ & $75,13 \mathrm{a}$ & $10,22 \mathrm{a}$ & $35,67 \mathrm{a}$ & $135,17 \mathrm{a}$ \\
$100 \% \mathrm{NPK}$ & $68,84 \mathrm{a}$ & $12,22 \mathrm{a}$ & $37,00 \mathrm{a}$ & $143,17 \mathrm{a}$ \\
\hline \multicolumn{4}{l}{ Keterangan: Angka pada kolom yang diikuti huruf yang sama menunjukkan tidak ada beda } \\
nyata berdasarkan uji F pada taraf nyata 5\%.
\end{tabular}

Tabel 2 menunjukkan bahwa pemberian POC pada berbagai konsentrasi cenderung lebih baik dibanding dengan perlakuan $100 \%$ pupuk NPK. Pemberian POC dengan konsentrasi $20 \mathrm{ml} / \mathrm{l}$ memiliki tinggi tanaman lebih tinggi dibanding perlakuan lain. Hal ini disebabkan bahan-bahan organik dalam POC yang dapat membantu menyediakan hara yang dibutuhkan tanaman.

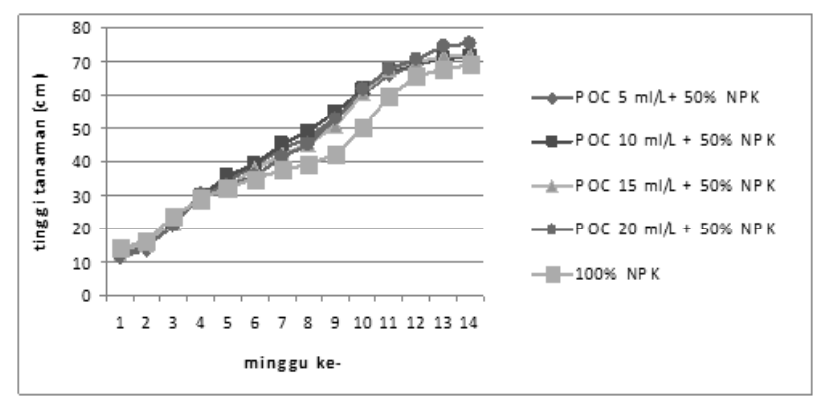

Gambar 2. Perkembangan Tinggi Tanaman Padi Selama Diberikan Perlakuan

Sebagai perbandingan tinggi tanaman padi Ciherang pada masa vegetatif maksimum di lahan sawah mencapai 107-115 cm (Marpaung, 2002). Hal ini dapat dijelaskan bahwa pemberian POC yang diperkaya Rhizobakteri belum dapat meningkatkan pertumbuhan padi Ciherang pada kondisi cekaman kekeringan. Kondisi cekaman kekeringan hingga 40\% menghambat penyerapan hara, sehingga berpengaruh pula pada pemanjangan batang.

Hasil analisis pada jumlah anakan, jumlah daun dan luas daun menunjukkan bahwa tidak ada beda nyata antar perlakuan pada parameter tersebut. Hal ini menunjukkan bahwa pemberian POC yang diperkaya Rhizobakteri Osmotoleran lebih efisien dalam pemberian pupuk NPK. Hal ini dikarenakan peran Rhizobakteri Osmotoleran selain dapat meningkatkan ketahanan tanaman dalam kondisi kekeringan juga dapat menfiksasi N. Rerata jumlah anakan, jumlah daun dan luas daun disajikan pada Tabel 2, sedangkan perkembangan jumlah anakan, jumlah daun dan luas daun disajikan dengan grafik pada Gambar 3,4 dan 5.

Kondisi kering akibat cekaman kekurangan air menghambat pertumbuhan vegetatif tanaman dalam membentuk anakan, sehingga jumlah anakan yang dihasilkan tergolong sedikit. Rendahnya jumlah anakan pada kondisi kering mengindikasikan transpor nutrien yang tidak 
berjalan lancar karena tanaman dalam kondisi tercekam lingkungan.

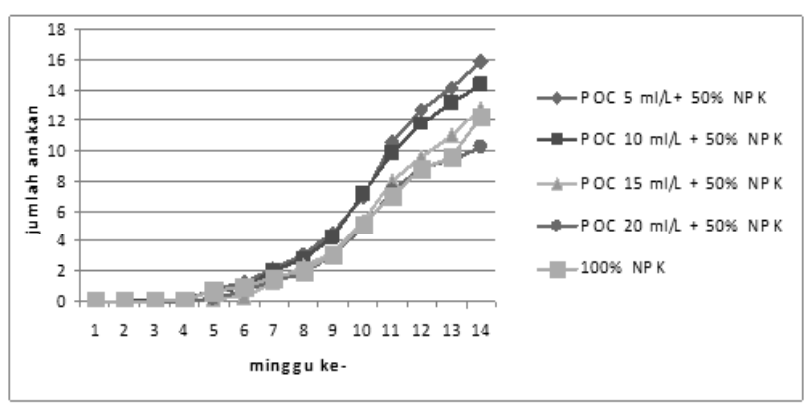

Gambar 3. Pertambahan Jumlah Anakan pada Tanaman Padi Ciherang yang Diberi Perlakuan

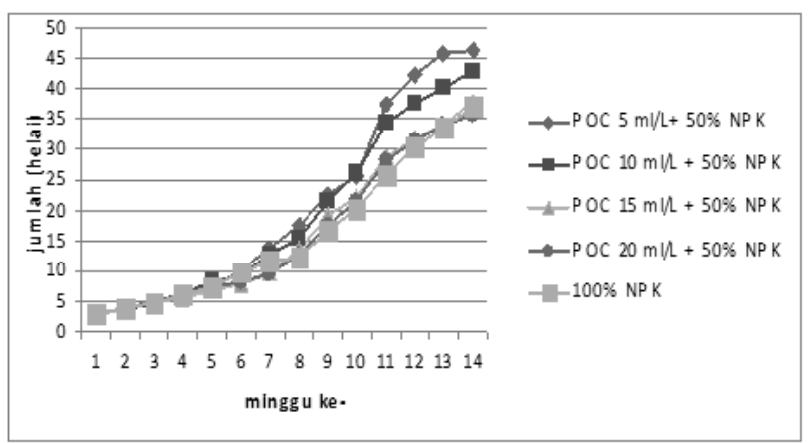

Gambar 4. Pertambahan Jumlah Daun pada tanaman Padi Ciherang yang Diberi Perlakuan

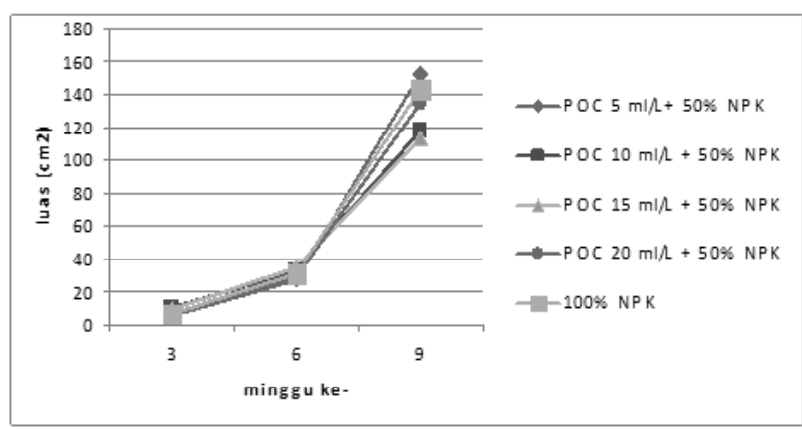

Gambar 5. Luas Daun pada Umur 3, 6 dan 9 Minggu pada Tanaman Padi Ciherang yang Diberi Perlakuan

Berdasarkan Gambar 3, 4 dan 5 pada parameter jumlah anakan, jumlah dan luas daun, pemberian POC dengan konsentrasi $5 \mathrm{ml} / \mathrm{l}$ cenderung lebih tinggi dibandingkan dengan perlakuan lainnya walaupun tidak secara nyata. Hal ini dikarenakan pemberian POC konsentra- si $5 \mathrm{ml} / \mathrm{L}$ dengan penambahan $50 \%$ dosis pupuk NPK sesuai dengan tuntutan tanaman, sehingga tanaman lebih mudah menyerap unsur hara dari tanah walaupun dalam kondisi kekeringan. Penambahan Rhizobakteri menunjukkan peran pada jumlah anakan, jumlah daun, dan luas daun tanaman padi Ciherang walaupun belum secara nyata.

Hasil analisis panjang, berat segar dan berat kering akar menunjukkan bahwa tidak ada beda nyata antar perlakuan. Hal ini menunjukkan bahwa pemberian POC diperkaya Rhizobakteri Osmotoleran selain dapat meningkatkan ketahanan tanaman dalam kondisi cekaman kekeringan, juga dapat memfiksasi N, sehingga pemberian pupuk NPK lebih efisien. Rerata panjang, berat segar dan berat kering akar disajikan pada Tabel 3. Perkembangan panjang, berat segar dan berat kering akar disajikan dalam bentuk grafik pada Gambar 6, 7, dan 8.

Tabel 3. Rerata Panjang Akar, Berat Segar Akar, Berat Kering Akar, Berat Segar Tanaman dan Berat Kering Tanaman

\begin{tabular}{lccccc}
\hline Perlakuan & $\begin{array}{c}\text { Panjang } \\
\text { Akar }(\mathrm{cm})\end{array}$ & $\begin{array}{c}\text { Berat } \\
\text { Segar } \\
\text { Akar }(\mathrm{g})\end{array}$ & $\begin{array}{c}\text { Berat } \\
\text { Kering } \\
\text { Akar }(\mathrm{g})\end{array}$ & $\begin{array}{c}\text { Berat } \\
\text { Segar } \\
\text { Tanaman } \\
(\mathrm{g})\end{array}$ & $\begin{array}{c}\text { Berat } \\
\text { Kering } \\
\text { Tanaman } \\
(\mathrm{g})\end{array}$ \\
\hline POC $5 \mathrm{ml} / \mathrm{l}+50 \% \mathrm{NPK}$ & $6,83 \mathrm{a}$ & $1,76 \mathrm{a}$ & $0,64 \mathrm{a}$ & $6,83 \mathrm{a}$ & $1,88 \mathrm{a}$ \\
POC $10 \mathrm{ml} / \mathrm{l}+50 \% \mathrm{NPK}$ & $5,37 \mathrm{a}$ & $1,27 \mathrm{a}$ & $0,43 \mathrm{a}$ & $5,37 \mathrm{a}$ & $1,41 \mathrm{a}$ \\
POC $15 \mathrm{ml} / \mathrm{I}+50 \% \mathrm{NPK}$ & $5,29 \mathrm{a}$ & $1,07 \mathrm{a}$ & $0,44 \mathrm{a}$ & $5,29 \mathrm{a}$ & $1,40 \mathrm{a}$ \\
POC $20 \mathrm{ml} / \mathrm{l}+50 \% \mathrm{NPK}$ & $6,07 \mathrm{a}$ & $1,28 \mathrm{a}$ & $0,45 \mathrm{a}$ & $6,07 \mathrm{a}$ & $1,60 \mathrm{a}$ \\
$100 \% \mathrm{NPK}$ & $6,10 \mathrm{a}$ & $1,31 \mathrm{a}$ & $0,40 \mathrm{a}$ & $6,10 \mathrm{a}$ & $1,36 \mathrm{a}$ \\
\hline
\end{tabular}

Keterangan: Angka pada kolom yang diikuti huruf yang sama menunjukkan tidak ada beda nyata berdasarkan uji $F$ pada taraf nyata $5 \%$.

Berdasarkan Tabel 3 dapat diketahui bahwa pemberian POC dengan berbagai konsentrasi belum dapat meningkatkan panjang, berat segar dan berat kering akar tanaman padi Ciherang pada kondisi cekaman kekeringan. Hal ini dikarenakan faktor lingkungan yaitu cekaman kekeringan lebih berpengaruh pada tanaman, sehingga diduga tanaman lebih cenderung melakukan 
perubahan morfologi sebagai respon terhadap kekeringan. Hasanah, (2008) menyatakan bahwa pada kondisi kering akar akan memunculkan naluri untuk bertahan hidup dengan cara memperkuat akar yang sudah ada daripada membentuk akar baru sehingga akar pada kondisi kering akan tampak menjadi lebih besar dan pendek.

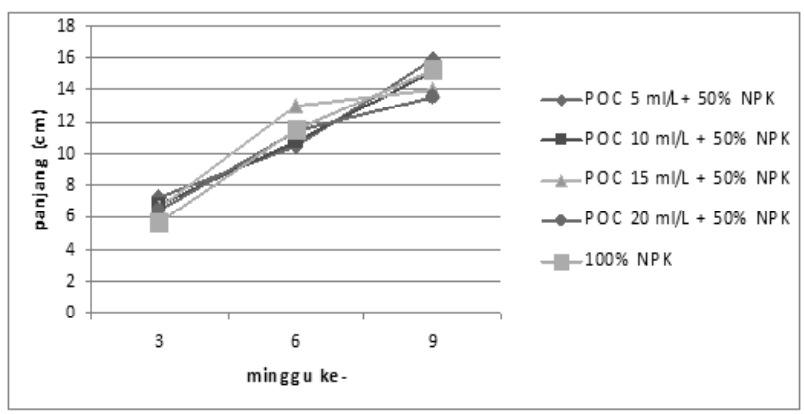

Gambar 6. Perkembangan Panjang Akar pada Umur 3, 6 dan 9 Minggu pada Pertumbuhan Tanaman Padi Ciherang

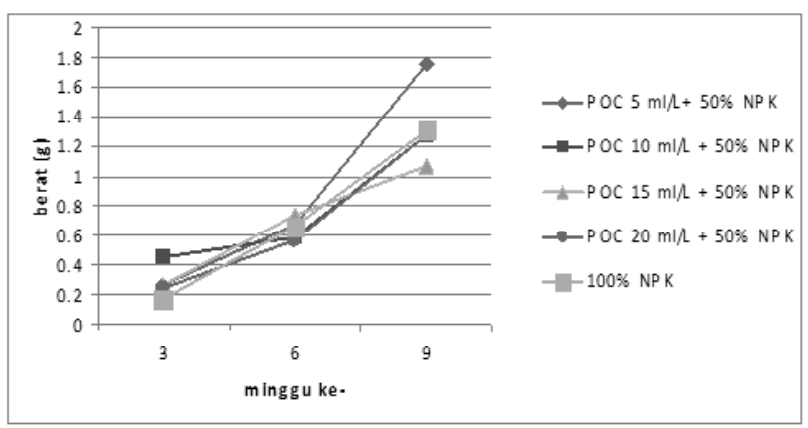

Gambar 7. Berat Segar Akar pada Umur 3, 6 dan 9 Minggu pada Pertumbuhan Tanaman Padi Ciherang

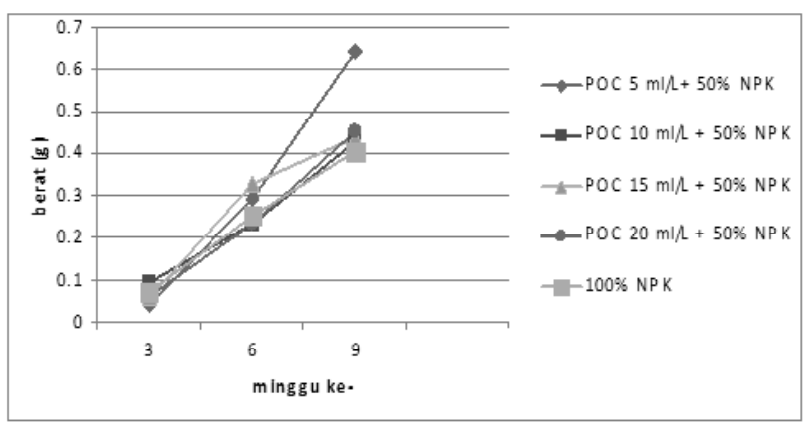

Gambar 8. Berat Kering Akar pada Umur 3, 6 dan 9 Minggu pada Pertumbuhan Tanaman Padi Ciherang
Berdasarkan Gambar 6, 7, dan 8 pemberian POC dengan konsentrasi $5 \mathrm{ml} / \mathrm{l}$ cenderung lebih tinggi dibandingkan dengan perlakuan lainnya walaupun tidak secara nyata. Hal ini dikarenakan pemberian POC konsentrasi $5 \mathrm{ml} / \mathrm{L}$ dengan penambahan 50\% dosis pupuk NPK sesuai dengan tuntutan tanaman, sehingga tanaman lebih mudah menyerap unsur hara dari tanah walaupun dalam kondisi kekeringan. Hal ini didukung oleh data luas daun yang menunjukkan bahwa pemberian perlakuan POC konsentrasi $5 \mathrm{ml} / \mathrm{l}$ memiliki luas daun yang lebih baik, dengan demikian proses fisiologis pada tanaman padi juga akan lebih baik.

Hasil analisis berat segar dan kering tanaman tanaman padi Ciherang menunjukkan bahwa tidak ada beda nyata antar perlakuan baik pada berat segar atau berat kering tanaman. Berdasarkan hasil analisis dapat dijelaskan bahwa pemberian POC diperkaya Rhizobakteri Osmotoleran ditambah 50\% pupuk NPK dapat memberikan hasil yang sama dengan perlakuan $100 \%$ pupuk NPK. Hal ini dikarenakan peran Rhizobakteri Osmotoleran yang dapat memfiksasi $\mathrm{N}$ sekaligus meningkatkan ketahanan tanaman dalam kondisi cekaman kekeringan. Rerata berat segar dan kering tanaman disajikan pada Tabel 3. Penambahan berat segar dan kering tanaman disajikan pada Gambar 9 dan 10.

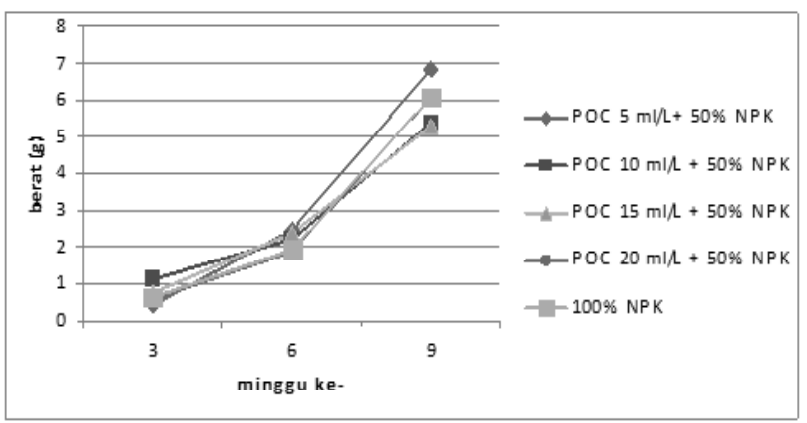

Gambar 9. Berat Segar Tanaman pada Umur Tanam 3, 6 dan 9 Minggul 


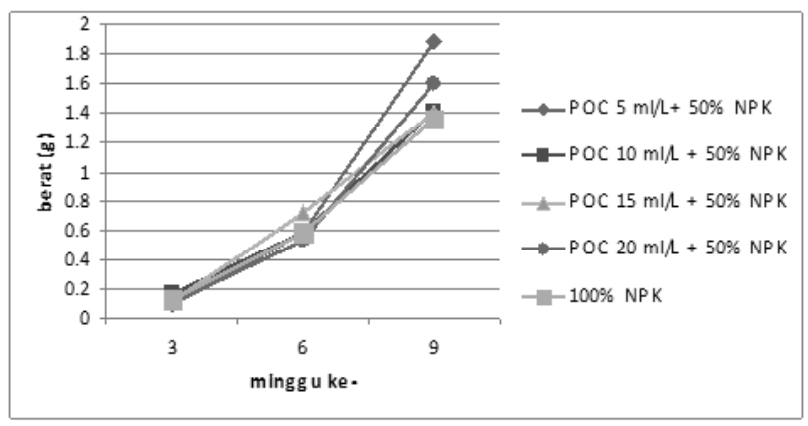

Gambar 10. Berat Kering Tanaman pada Umur Tanam 3, 6 dan 9 Minggu

Tabel 3 menunjukkan bahwa rerata berat segar dan kering tanaman semua perlakuan hampir sama. Menurut Gardner et al., (1991) berat segar tanaman menunjukkan banyaknya fotosintat yang dibentuk dan disimpan oleh tanaman. Proses fisiologis dalam tubuh tanaman dapat terhambat jika ketersediaan air terbatas. Berat kering tanaman merupakan akibat dari penimbunan hasil bersih asimilasi $\mathrm{CO}_{2}$ selama pertumbuhan. Hal ini karena asimilasi $\mathrm{CO}_{2}$ merupakan hasil penyerapan energi matahari dan akibat radiasi matahari yang di absorbsi dan efisiensi pemanfaatan energi tersebut untuk fiksasi $\mathrm{O}_{2}$.

Berdasarkan Gambar 9 dan 10 pada parameter berat segar dan kering tanaman pemberian POC dengan konsentrasi $5 \mathrm{ml} / \mathrm{l}$ cenderung lebih baik dibandingkan dengan perlakuan lainnya walaupun tidak secara nyata. Hal ini dikarenakan pemberian POC dengan konsentrasi $5 \mathrm{ml} / \mathrm{L}$ dengan penambahan $50 \%$ dosis pupuk NPK sesuai dengan tuntutan tanaman, sehingga tanaman akan lebih mudah menyerap unsur hara dari tanah walaupun dalam kondisi kekeringan. Hal ini didukung dengan data luas daun yang menunjukkan bahwa pemberian perlakuan POC dengan konsentrasi $5 \mathrm{ml} / \mathrm{l}$ memiliki luas daun yang lebih baik, dengan demikian proses fotosintesis akan berjalan lebih lancar, sehingga timbunan fotosintat juga akan lebih banyak..
Meninjau dari data dinamika populasi Rhizobakteri Osmotoleran menunjukkan bahwa Rhizobakteri Osmotoleran berperan pada pembentukan hasil fotosintat walaupun secara tidak nyata. Hal ini dikarenakan peran Rhizobakteri Osmotoleran yang dapat meningkatkan ketahanan tanaman dalam kondisi cekaman kekeringan sekaligus dapat memfiksasi N. Hasil penelitian Supangkat, (2002) menyatakan bahwa berat kering tajuk tertinggi cenderung dicapai tanaman yang diinokulasi dengan isolat A-82 baik pada kadar lengas $80 \%$ dan $40 \%$.

\section{Komponen Hasil Tanaman Padi}

Hasil analisis varian terhadap persentase anakan produktif, jumlah malai, berat 1000 biji, berat biji per tanaman, dan persentase biji hijau menunjukkan ada beda nyata antar perlakuan pada parameter persentase anakan produktif. Hasil analisis juga menunjukkan tidak ada beda nyata antar perlakuan pada parameter jumlah malai, berat 1000 biji, berat biji per tanaman dan persentase biji hijau. Berdasarkan hasil analisis dapat dijelaskan bahwa pemberian POC diperkaya Rhizobakteri Osmotoleran cenderung lebih baik dibandingkan dengan pemberian perlakuan 100\% pupuk NPK tanpa penambahan Rhizobakteri Osmotoleran. Hal ini menunjukkan bahwa peran Rhizobakteri Osmotoleran yang dapat meningkatkan ketahanan terhadap kondisi cekaman kekeringan sekaligus memfiksasi N, sehingga dapat meningkatkan hasil tanaman padi. Rerata jumlah malai dan berat biji per tanaman serta berat 1000 biji tanaman disajikan pada Tabel 4.

Pada Tabel 4 dapat dijelaskan bahwa pemberian POC dengan konsentrasi $20 \mathrm{ml} / \mathrm{l}$ menunjukkan hasil yang paling tinggi terhadap persentase anakan produktif tetapi tidak berbeda nyata dengan perlakuan pemberian POC dengan 
konsentrasi $10 \mathrm{ml} / \mathrm{l}$, kemudian diikuti dengan perlakuan pemberian POC dengan konsentrasi $5 \mathrm{ml} / \mathrm{l}, 100 \%$ pupuk NPK dan POC konsentrasi $15 \mathrm{ml} / \mathrm{l}$. Sebagai perbandingan deskripsi tanaman padi Ciherang di lahan sawah, menurut Marpaung, (2002) tanaman padi Ciherang memiliki jumlah anakan produktif sekitar 14-17 anakan. Jumlah anakan produktif yang sedikit dipengaruhi oleh kondisi cekaman kekeringan.

Tabel 4. Rerata Persentase Anakan Produktif, Jumlah Malai, Berat 1000 Biji, Berat Biji Per Tanaman dan Persentase Biji Hijau

\begin{tabular}{cccccc}
\hline Perlakuan & $\begin{array}{c}\text { Persentase } \\
\text { Anakan } \\
\text { Produktif } \\
(\%)\end{array}$ & $\begin{array}{c}\text { Jumlah } \\
\text { Malai }\end{array}$ & $\begin{array}{c}\text { Berat } \\
1000 \text { Biji } \\
(\mathrm{g})\end{array}$ & $\begin{array}{c}\text { Berat } \\
\text { Biji per } \\
\text { Tanaman } \\
(\mathrm{g})\end{array}$ & $\begin{array}{c}\text { Persentase } \\
\text { Biji Hijau } \\
(\%)\end{array}$ \\
\hline POC $5 \mathrm{ml} / \mathrm{l}+50 \% \mathrm{NPK}$ & $53,3 \mathrm{~b}$ & $8,44 \mathrm{a}$ & $17,7 \mathrm{a}$ & $4,48 \mathrm{a}$ & $14,72 \mathrm{a}$ \\
POC $10 \mathrm{ml} / \mathrm{l}+50 \% \mathrm{NPK}$ & $59,55 \mathrm{ab}$ & $8,56 \mathrm{a}$ & $17,7 \mathrm{a}$ & $4,77 \mathrm{a}$ & $10,60 \mathrm{a}$ \\
POC $15 \mathrm{ml} / \mathrm{l}+50 \% \mathrm{NPK}$ & $50,27 \mathrm{~b}$ & $6,11 \mathrm{a}$ & $19,3 \mathrm{a}$ & $5,33 \mathrm{a}$ & $3,17 \mathrm{a}$ \\
POC $20 \mathrm{ml} / \mathrm{l}+50 \% \mathrm{NPK}$ & $69,32 \mathrm{a}$ & $7,11 \mathrm{a}$ & $18,0 \mathrm{a}$ & $4,74 \mathrm{a}$ & $14,02 \mathrm{a}$ \\
$100 \% \mathrm{NPK}$ & $52,7 \mathrm{~b}$ & $6,44 \mathrm{a}$ & $18,0 \mathrm{a}$ & $4,17 \mathrm{a}$ & $13,39 \mathrm{a}$ \\
\hline
\end{tabular}

Keterangan: Angka pada kolom yang diikuti huruf yang sama menunjukkan tidak ada beda nyata berdasarkan uji F pada taraf nyata $5 \%$.

Pada Tabel 4 dapat dijelaskan bahwa semua perlakuan memiliki pengaruh yang sama terhadap jumlah malai, berat 1000 biji, berat biji per tanaman dan persentase biji hijau. Hal ini dikarenakan pengaruh stres tanaman akibat kurangnya air lebih besar, sehingga tanaman tumbuh kurang baik. Pemberian POC yang sudah diperkaya Rhizobakteri Osmotoleran belum dapat membantu tanaman untuk meningkatkan hasil dalam kondisi cekaman kekeringan.

Tabel 4 menunjukkan bahwa perlakuan pemberian POC dengan konsentrasi $10 \mathrm{ml} / 1$ memiliki jumlah malai cenderung lebih banyak walaupun tidak berbeda nyata dengan perlakuan lainnya. Diikuti perlakuan pemberian POC dengan konsentrasi 5 ml/1, 20 ml/1, 100\% pupuk NPK dan POC konsentrasi $15 \mathrm{ml} / \mathrm{l}$. Data pada tabel 4 dapat dijelaskan bahwa pemberian perlakuan POC dengan konsentrasi $15 \mathrm{ml} / \mathrm{l}$ memiliki nilai berat 1000 biji cenderung lebih tinggi walaupun tidak berbeda nyata dengan perlakuan lainnya. Hal ini menunjukkan biji pada perlakuan POC dengan konsentrasi 15 $\mathrm{ml} / \mathrm{l}$ lebih penuh pengisian bulirnya. Menurut Marpaung (2002), berat 1000 biji tanaman padi Ciherang pada lahan sawah yaitu $28 \mathrm{~g}$. Dari data tersebut menunjukkan pengisian bulir padi pada semua perlakuan belum dapat mencapai standar. Hal ini disebabkan oleh kondisi cekaman kekeringan yang mengakibatkan terhambatnya proses pengisian bulir.

Pada tabel 4 dapat dijelaskan bahwa pemberian perlakuan POC dengan konsentrasi 15 ml/1 memiliki nilai berat biji per tanaman cenderung lebih tinggi dibandingkan dengan perlakuan lainnya walaupun tidak secara nyata. Hal ini menunjukkan bahwa banyaknya malai yang keluar belum tentu dapat meningkatkan berat biji per tanaman.

Sementara perlakuan pemberian POC dengan konsentrasi $15 \mathrm{ml} / \mathrm{l}$ memiliki persentase berat biji hijau cenderung lebih rendah dibandingkan dengan perlakuan lainnya walaupun tidak berbeda nyata (Tabel 4). Hal ini menunjukkan bahwa perlakuan pemberian POC dengan konsentrasi $15 \mathrm{ml} / 1$ lebih cepat proses pematangan bijinya. Percepatan pematangan biji diduga karenak tanaman mengalami stres akibat kondisi kekeringan. Perkembangan jumlah malai per tanaman disajikan pada Gambar 11.

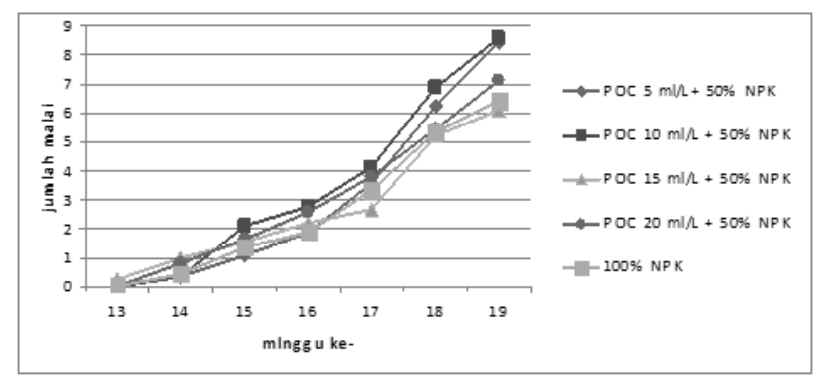

Gambar 11. Perkembangan Jumlah Malai dari Umur 13 Minggu Sampai dengan Umur 19 Minggu 
Translokasi fotosintat dilakukan oleh floem ke organ biji. Air merupakan bahan yang berfungsi sebagai transpor zat -zat (fotosintat dan unsur hara) dari sel ke sel dan organ ke organ. Pada kondisi cekaman kekeringan tanaman padi Ciherang masih mampu menghasilkan biji namun jika dibandingkan dengan berat biji panen padi Ciherang pada kondisi normal yaitu 5-7 ton/Ha (Marpaung, 2002), hasil berat biji per tanaman masih jauh dari harapan. Kondisi stres air akibat kekurangan air menjadi penyebab menurunnya laju translokasi fotosintat tanaman. Pemberian POC diperkaya Rhizobakteri Osmotoleran lebih efisien mempengaruhi berat biji per tanaman.

Pada semua perlakuan beberapa biji tidak berisi, hal ini disebabkan oleh kurangtersedianya hara tanah akibat keadaan cekaman kekeringan. Menurut Gardner, et al, (1991) pada tingkat akhir perkembangan polong, kekurangan air tetap mengakibatkan gugurnya polong, perkembangan polong jelek (lebih sedikit biji dalam polong, menurunnya fotosintesis (berkurangnya berat per biji) dan akhirnya menyebabkan kehilangan hasil biji yang lebih parah.

Secara umum, pemberian POC yang sudah diperkaya Rhizobakteri Osmotoleran belum mampu secara signifikan meningkatkan pertumbuhan dan hasil tanaman padi Ciherang pada kondisi cekaman kekeringan, namun ada kecenderungan perlakuan pemberian POC lebih baik dibandingkan dengan perlakuan 100\% pupuk NPK pada parameter pertumbuhan dan hasil tanaman padi. Hal ini dikarenakan peran Rhizobakteri Osmotoleran yang mampu meningkatkan ketahanan tanaman dalam kondisi cekaman kekeringan dan sekaligus memfiksasi $\mathrm{N}$, sehingga pemupukan lebih efisien. Perlakuan pemberian POC dengan konsentrasi $5 \mathrm{ml} / \mathrm{l}$ cenderung lebih baik pada parameter pertumbuhan padi
Ciherang dibanding perlakuan lainnya, namun pertumbuhan yang baik belum tentu dapat memberikan hasil yang baik. Parameter hasil tanaman padi cenderung lebih baik pada perlakuan pemberian POC dengan konsentrasi $15 \mathrm{ml} / \mathrm{l}$.

\section{SIMPULAN}

Hasil penelitian menunjukkan bahwa pemberian Pupuk Organik diperkaya Rhizobakteri Osmotoleran dapat mengurangi konsumsi pupuk NPK hingga 50\%. Perlakuan pemberian Pupuk Organik Cair dengan konsentrasi $15 \mathrm{ml} / 1+$ pupuk NPK 50\% dosis anjuran cenderung lebih baik mempengaruhi pertumbuhan dan hasil tanaman padi Ciherang pada kondisi cekaman kekeringan.

Penelitian ini disarankan untuk dikaji lebih lanjut pada berbagai jenis tanah untuk mendapatkan pengaruh konsentrasi yang tepat untuk diaplikasikan di lahan yang mengalami kekeringan. Perlu dikaji pula mengenai pemberian perlakuan POC diperkaya Rhizobakteri Osmotoleran saja tanpa penambahan pupuk anorganik. Perlu dikaji lebih lanjut mengenai perbandingan produksi tanaman padi di lahan sawah tanpa pemberian perlakuan POC diperkaya Rhizobakteri Osmotoleran dengan lahan kering dengan penambahan POC diperkaya Rhizobakteri Osmotoleran, juga perlu dikaji lebih lanjut pengaruh pemberian POC diperkaya Rhizobakteri Osmotoleran pada berbagai kadar cekaman kekeringan.

\section{DAFTAR PUSTAKA}

Anonim, 2008, Data Strategis BPS, Badan Pusat Statistik, Indonesia.

Gardner, F.P.,R.B. Pearce and R.L. Mitchell. 1991. Fisiologi Tanaman Budidaya. Terjemahan H. Susilo. Universitas Indinesia. Jakarta.

Hasanah,N.A.U, A._Astuti, dan L. Utari. 2008. Kajian Aktivitas Rhizobakteri Fiksasi N-Tahan Cekaman Kekeringan Dengan Berbagai Kondidi Air dan Macam Inokulum Pada Padi MerahPutih RI-1. Fakultas Pertanian UMY. Skripsi (tidak dipublikasikan). 

74 Planta Tropika Journal of Agro Science
Vol. 4 No. 2/ Agustus 2016

Khoiriyah, S. 2009. Uji Viabilitas dan Efektifitas Rhizobakteri Osmotoleran Pada Berbagai Formulasi dan Konsentrasi Pupuk Organik Cair. Fakultas Pertanian UMY. Skripsi Mahasiswa (Tidak Dipublikasikan).

Marpaung. I. S., 2002. Mengenal Padi Varietas Widas dan Ciherang. Lembar Informasi Pertanian. BPTP Sumatra Selatan.

Purwoko, T. 2007. Fisiologi Mikrobia. Bumi Aksara. Jakarta. 257 hal

Supangkat, G. 2002. Kajian Peranan Inokulasi Rhizobakteri Osmotoleran Pada Tanaman Padi di Tanah Pasir Pantai. Tesis UGM. Yogyakarta. 